\title{
PERBEDAAN TINGKAT PROFESIONALISME KERJA AUDITOR DILIHAT DARI JENIS KELAMIN, JABATAN, DAN JENIS AFILIASI KANTOR AKUNTAN PUBLIK
}

\author{
Rifqi Novriyandana \\ Universitas Lambung Mangkurat \\ rifqi.nouriyandana@gmail.com
}

\begin{abstract}
Profesionalism is one of the important thing in audit of public accountant. Public accountants have role and ethics when doing their job. Purpose of this research is to get the empirical evidence about difference of auditor profesionalism, if seen from sex, type of affiliation public accountant firm, and position of accountant in public accountant firm by using profesionalism instrument develop by Hall (1968) and Snizek (1972) combine with Meyer and Allen (1984).

The sample of this research is auditor at java island, sample was taken by clustered sampling method. Collecting data with direct observation to the public accountants firm in java island by using questioner. Gathered sample counted 136 with 100\% respons rate, so all of questioner is back. Examination of hyphothesis use t-test.

The result of this research, if seen profesionalism auditor from sex is not found the difference of profesionalism, it means between man and women have same the level of profesionalism. Based on position level at public accountant firm there is difference, it means there is difference level of profesionalism auditor seen by hierarchy. Based on type of affiiation accountans in public accountant firm there is not difference, it means accountants who work at accountant public local and accountant public foreign affiliation are the same level of profesionalism.
\end{abstract}

Keywords: Profesionalism auditor, sex, position level at public accountant (hierarchy), type of accountant public firm.

\begin{abstract}
Abstrak
Profesionalisme adalah salah satu hal yang penting dalam audit pada akuntan publik. Akuntan publik memiliki peranan dan etika ketika melakukan pekerjaan mereka. Tujuan dari penelitian ini adalah untuk mendapatkan bukti empiris tentang perbedaan profesionalisme auditor, jika dilihat dari jenis kelamin, jenis perusahaan afiliasi akuntan publik, dan posisi/tingkat jabatan akuntan di kantor akuntan publik dengan menggunakan instrumen profesionalisme mengembangkan oleh Hall (1968) dan Snizek (1972) menggabungkan dengan Meyer dan Allen (1984).

Sampel dari penelitian ini adalah auditor di pulau Jawa, sampel diambil dengan metode clustered sampling. Pengumpulan data dengan observasi langsung ke akuntan publik di pulau Jawa dengan menggunakan kuesioner. Sampel dikumpulkan sebanyak 136 dengan $100 \%$ tingkat pengembalian, sehingga semua kuesioner kembali. Pemeriksaan penggunaan hyphothesis t-test.

Hasil penelitian ini, jika dilihat profesionalisme auditor dari sex tidak ditemukan perbedaan profesionalisme, artinya antara pria dan wanita memiliki tingkat profesionalisme yang sama. Berdasarkan tingkat jabatan di kantor akuntan publik terdapat perbedaan, itu berarti ada perbedaan tingkat profesionalisme auditor jika dilihat dari hirarki jabatannya. Berdasarkan jenis kantor akuntan lokal dan berafiliasi asing tidak ada perbedaan, itu berarti akuntan yang bekerja di kantor akuntan publik afiliasi asingdan lokal memiliki tingkat profesionalisme yang sama.
\end{abstract}

Kata kunci: Profesionalisme auditor, jenis kelamin (sex), tingkat posisi pada akuntan publik (hirarki), jenis perusahaan akuntan publik. 


\section{PENDAHULUAN}

Profesi yang baik ialah profesi yang mampu memberikan kontribusi yang lebih baik kepada orang lain dengan keberadaan atau eksistensinya. Menurut Hall (1968), seorang profesional harus yakin benar bahwa suatu pekerjaan yang mereka kerjakan merupakan suatu yang penting, berkomitmen kuat pada pelayanan terhadap kepentingan publik, kebutuhan otonomi terhadap pelayanannya, memiliki peraturan hukum sendiri dalam menjalankan tugasnya, dan memiliki komunitas dengan sesama profesi. Profesionalisme merupakan suatu syarat yang harus dimiliki oleh setiap individu dalam menjalankan pekerjaannya.

Isu gender masih semarak diperbincangkan dalam banyak forum dan seminar. Salah satu pembahasan di dalamnya adalah persoalan kesetaraan gender. Wanita ingin mendapatkan kesetaraan dalam memperoleh haknya serta wewenang agar dapat menjadi salah satu bagian yang mampu memberikan suatu keputusan. Wanita ingin menjadi seorang pemimpin baik dalam lingkungan organisasi maupun pemerintahan.

Kantor Akuntan Publik di Indonesia pada dasarnya masih diragukan keindependesiannya. Pada dasarnya masih terdapat trade off dalam pelaksanaan tugsnya, klien sebagai konsumen biasanya masih meminta agar akuntan dapat bertoleransi dalam hal pelaporan temuan yang diperoleh pada saat proses pelaksanaan audit. Oleh karena itu laporan audit masih memiliki kelemahan dalam pengungkapan, hal ini terbukti dengan masih banyaknya kasus yang terjadi baik pada Kantor Akuntan Publik ternama yang berafiliasi dengan asing maupun Kantor Akuntan Publik lokal.

Profesi auditor memiliki jenjang karir yang jelas seiring dengan meningkatnya akumulasi jam penugasan audit. Semakin lama auditor melaksanakan tugas maka dapat memenuhi syarat untuk kenaikan jabatannya. Hal ini menunjukkan bahwa jam audit menunjukkan kelayakan seorang auditor untuk menduduki suatu jabatan. Naiknya jabatan seorang auditor seharusnya akan meningkatkan profesionalisme auditor dalam menjalankan tugasnya. Dengan asumsi semakin lama auditor bekerja, justifikasi auditor menjadi semakin baik dan matang dalam memecahkan setiap masalah dalam tugasnya.

Melihat adanya pro dan kontra pada penelitian sebelumnya maka, peneliti berinisiatif untuk melakukan penelitian tentang profesionalisme auditor ini.Penelitian ini difokuskan pada persoalan profesionalisme dengan mengukur tingkat profesionalisme tersebut pada auditor yang bekerja pada kantor akuntan publik. Ada tiga aspek yang menjadi pokok dalam penelitian ini antara lain menguji profesionalisme auditor melalui perbedaan jenis kelamin, perbedaan jabatan auditor, serta perbedaan jenis afiliasi kantor akuntan publik.

Berdasarkan latar belakang penelitian terdapat beberapa masalah yang perlu dikaji lebih dalam terkait dengan tingkat profesionalisme auditor di Indonesia. Permasalahan kesenjangan gender dalam operasional kerja akuntan publik harus mendapat perhatian yang serius dalam pengembangan karir. Pada struktur kantor akuntan publik, jabatan belum menjamin tingkat profesionalisme dari seorang auditor. Seorang auditor dengan jabatan tinggi kemungkinan besar akan mengalami penurunan tingkat profesionalisme kerja. Idealisme seorang auditor dalam mengemban tugas semestinya menjadi pegangan teguh dalam melaksanakan tugasnya. Perihal terakhir yang menjadi permasalahan yaitu jenis afiliasi kantor akuntan publik. Kantor akuntan publik berafiliasi asing semestinya mempunyai tingkat profesionalisme yang lebih tinggi dibandingkan dengan kantor akuntan publik lokal. Realitanya masih ada beberapa kasus yang terjadi yaitu kantor akuntan publik afiliasi asing tidak independen dalam melaksanakan tugasnya. Contohnya pada kasus Bank Lippo, ada sembilan Kantor Akuntan Publik yang terbukti melanggar kode etik profesi yaitu dengan menerbitkan laporan keuangan palsu. Laporan keuangan Bank Lippo dilaporkan sehat, tetapi proses pembuatan laporan keuangannya terbukti melanggar standar 
audit. Hasil laporan keuangan tersebut diketahui menyalahi standar audit karena tidak lama setelah diterbitkan, bank tersebut bangkrut. Perilaku ini mencerminkan ketidakprofesionalan kantor akuntan publik afiliasi asing dalam menjalankan tugas dan fungsinya.

Permasalahan kesenjangan gender dalam operasional kerja akuntan publik harus mendapat perhatian yang serius dalam pengembangan karir. Pada struktur kantor akuntan publik, jabatan belum menjamin tingkat profesionalisme dari seorang auditor. Seorang auditor dengan jabatan tinggi kemungkinan besar akan mengalami penurunan tingkat profesionalisme kerja. Idealisme seorang auditor dalam mengemban tugas semestinya menjadi pegangan teguh dalam melaksanakan tugasnya. Perihal terakhir yang menjadi permasalahan yaitu jenis afiliasi kantor akuntan publik. Kantor akuntan publik berafiliasi asing semestinya mempunyai tingkat profesionalisme yang lebih tinggi dibandingkan dengan kantor akuntan publik lokal. Realitanya masih ada beberapa kasus yang terjadi yaitu kantor akuntan publik afiliasi asing tidak independen dalam melaksanakan tugasnya. Contohnya pada kasus Bank Lippo, ada sembilan Kantor Akuntan Publik yang terbukti melanggar kode etik profesi yaitu dengan menerbitkan laporan keuangan palsu. Laporan keuangan Bank Lippo dilaporkan sehat, tetapi proses pembuatan laporan keuangannya terbukti melanggar standar audit. Hasil laporan keuangan tersebut diketahui menyalahi standar audit karena tidak lama setelah diterbitkan, bank tersebut bangkrut. Perilaku ini mencerminkan ketidakprofesionalan kantor akuntan publik afiliasi asing dalam menjalankan tugas dan fungsinya.

Berdasarkan uraian sebelumnya maka penelitian ini merumuskan masalah sebagai berikut:_(1)_Apakah terdapat perbedaan Tingkat Profesionalisme antara auditor pria dan auditor wanita? (2) Apakah terdapat perbedaan Tingkat Profesionalisme auditor dilihat dari jabatannya di Kantor Akuntan Publik (KAP)? dan (3) Apakah terdapat perbedaan Tingkat Profesionalisme auditor pada kantor akuntan publik afiliasi asing dan kantor akuntan publik lokal?

\section{Teori Sosiologi Profesi}

Penelitian ini terkait dengan profesi akuntan sehingga dapat dikaitkan dengan teori sosiologi dan teori psikologi. Penelitian ini melihat perilaku manusia melalui aspek perbedaan jenis kelamin dan jabatannya dalam suatu lingkungan pekerjaan. Dalam perkembangannya perilaku selalu mengalami perubahan, hal ini juga yang terjadi pada setiap periode perkembangan manusia. Misal dengan adanya pemasalahan gender mengakibatkan wanita pada masa sekarang mendapat hak yang setara dengan pria. Untuk itu maka yang dijadikan teori dasar ialah teori sosiologi Kalbers dan Fogarty (1995) dan teori sosiologi klasik Aranya dan Ferris (1983). Teori tersebut menyatakan bahwa masyarakat mengakui kekuatan (power) dan prestise profesi karena para profesional memiliki ilmu pengetahuan yang terkait dengan kebutuhan dan nilainilai sentral dari sistem sosial. Oleh karena itu, menurut Vollmer dan Mills (1966), Moore (1970), Larson (1977), dalam Aranya dan Ferris (1983) dalam hasil penelitiannya menyatakan bahwa masyarakat mengharapkan para profesional untuk berkomitmen melayani masyarakat di atas kepentingan pribadinya dan melebihi insentif-insentif material.

\section{Komitmen Organisasi}

Komitmen organisasi didefinisikan sebagai kekuatan dalam mengidentifikasi individu karena keikutsertaanya sebagai bagian dari organisasi (Harrell et al,1986; Nouri \& Parker, 1998 dan Mowday, Steers, \& Porter, 1979) dalam Lord \& Dezoort (2001). Adapun konstruk yang dibangun oleh Aranya \& ferris (1983) karena beberapa alasan yaitu pertama, tingginya komitmen mendorong karyawan untuk melakukan yang terbaik bagi organisasi dari pada karyawan yang rendah komitmennya terhadap organisasi (Jauch, et al., 1978). Kedua, komitmen organisasi menjadi prediksi terbaik terhadap tingkat perputaran karyawan dari pada kepuasan kerja (Taylor, et al., 1996). Ketiga, komitmen organisasi digunakan sebagai suatu indikator dari 
efektivitas keseluruhan suatu organisasi (Steers, 1977.

Adapun dalam penelitian ini lebih merujuk pada penelitian Meyer, et al., (1990) dalam Shafer, et al., (2002) yang membedakan komitmen menjadi affective and continuance sebagai istilahnya. Kedua istilah ini muncul didasarkannya dari hasil penelitian Porter et al., (1974) dan Becker (1960). Dimana, Porter menggambarkan komitmen sebagai suatu kekuatan individu dan keterlibatannya dalam organisasi (Meyer et al., 1989). Untuk itu komitmen seperti yang diungkapkan diatas lebih dikenal sebagai komitmen affective yang identik untuk ditujukan pada komitmen terhadap organisasi. Sedangkan, Becker (1960) mendefinisikan komitmen sebagai suatu keikutsertaan dalam kegiatan organisasi secara konsisten. Komitmen seperti ini dikatakan sebagai komitmen continuance. Awalnya penelitian semacam ini hanya menggunakan konstruk tunggal tapi seiring dengan perkembangan organisasi penelitian lebih lanjut mengarah pada konstruk ganda. Konsep komitmen affective dkembangkan oleh Meyer \& Allen (1984) didasarkan pada individual organizational goal congruance yaitu individu bekerja sama dalam organisasi untuk mencapai tujuan bersama. Komitmen ini menggambarkan kemauan atau kekuatan dari seorang karyawan untuk terus bekerja di organisasinya karena karyawan tersebut merasa senang dan suka bekerja pada organisasi tersebut. Kemudian, komitmen continuance yang dikembangkan oleh Becker (1960) konsep ini merujuk pada kecenderungan seeorang karyawan tetap bekerja pada suatu organisasi karena tidak memiliki alternatif lain dalam bekerja atau dengan kata lain apabila dia keluar kerja maka akan menambah beban hidupnya. Jadi, manfaat untuk tetap bekerja pada organisasi tersebut masih dirasa lebih tinggi sehingga hal tersebut mencegah karyawan tersebut untuk mencari pekerjaan lain (Meyer \& Allen, 1984).

\section{Pengukuran Profesionalisme}

Berdasarkan dari hasil penelitian sebelumnya yang dilakukan dengan membedakan orang menjadi pekerja profesional dan tidak profesional yang dikategorikan berdasarkan jenis pekerjaan seseorang. Howell dan Dorfman (1986) dalam Swailes (2003), membuat tujuh skala untuk mengukur tingkat profesionalisme kerja seseorang adapun indikatornya ialah pendidikan, tingkat kemampuan dalam melakukan suatu pekerjaan, kehandalan dalam mengevaluasi kinerja, panduan, dan interkasi dengan orang-orang yang memiliki profesi yang sama, serta kebutuhan terhadap otonomi. Dalam pengukuran tingkat profesioanlisme tersebut masih dirasa tidak mengukur dengan kejelasan yang cukup terhadap sikap dan ideologi para profesional yang dijadikan objek, untuk itu kemudian kontribusi utama terhadap penelitian mengenai tingkat profesionalisme ini datang dari Hall (1968) yang mengukur profesionalisme dengan menitikberatkan pada perilaku. Kemudian hasil penelitian Hall (1968) ini diuji kembali oleh Snizek (1972), yang menemukan bahwa hanya setengah dari skala item profesional yang dikemukakan oleh Hall yang dianggap memadai sebagai pengukur profesionalisme. Seiring dengan perkembangan zaman akhirnya hasil temuan Snizek (1972) melalui Teori Hall (1968) mengenai profesionalisme terus digunakan oleh para peneliti selanjutnya dan pada akhirnya dapat digeneralisasi, yang terbukti salah satunya di Amerika utara.

Hipotesis penelitian dalam penelitian ini adala sebagai berikut: (1) Auditor wanita yang bekerja dikantor akuntan publik, memiliki perbedaan tingkat profesionalisme dengan auditor pria, (2) Perbedaan jabatan seorang auditor dalam Kantor Akuntan Publik, berdampak pada perbedaan tingkat profesionalismenya, dan (3) Auditor padaKantor Akuntan Publik Afiliasi Asing memiliki tingkat profesionalisme kerja yang lebih tinggi dibandingkan auditor pada Kantor Akuntan Publik Lokal.

\section{METODE PENELITIAN}

\section{Jenis dan Sumber Data}

Jenis data yang digunakan dalam penelitian ini ialah data yang langsung diperoleh dari objek. Data yang diambil secara langsung diungkapkan oleh objek 
dalam suatu instrumen penelitian. Didalamnya terdapat beberapa pertanyaan dengan tujuan untuk dapat dijadikan informasi sebagai data mentah dalam penelitian. Adapun sumber data diperoleh dari auditor pada kantor akuntan publik yang bekerja di Pulau Jawa. Data yang disebarkan dalam penelitian ini sebanyak 136 kuesioner. Data diambil secara langsung dengan mendatangi beberapa kantor akuntan publik yang berada di Pulau Jawa yaitu D.K.I. Jakarta, Semarang, D.I. Yogyakarta, dan Surabaya.

\section{Populasi dan Teknik Pengambilan Sampel}

Populasi penelitian ini ialah seluruh auditor yang bekerja di Kantor Akuntan Publik yang berada di Pulau Jawa. Sampel yang dipakai yaitu auditor yang memenuhi syarat atau kriteria sebagai objek penelitian. Metode pemilihan sampel dilakukan dengan Clustered sampling berdasarkan Nur Indriantoro dan Bambang Supono (1999), maksudnya ialah dengan membagi sampel penelitian menjadi kelompokkelompok berdasarkan perbedaan jenis kelamin, jabatan, dan jenis afiliasi kantor akuntan publiknya.

\section{Definisi Operasional dan Pengukuran Variabel}

Dapat diketahui bahwa dalam penelitian ini terdapat tiga variabel independen yaitu Jenis Kelamin, Jabatan, dan Jenis Afiliasi Kantor Akuntan Publik. Serta, terdapat satu variabel dependen yaitu Tingkat Profesionalisme. Jenis kelamin dalam penelitian ini dibedakan berdasarkan pria dan wanita. Kemudian, untuk variabel tingkatan jabatan ialah sesuai dengan struktur jabatan yang ada di kantor akuntan publik di Indonesia. Struktur jabatan tersebut meliputi partner atau rekan, manajer, senior auditor, dan junior auditor. Serta, jenis afiliasi KAP yang dilihat berdasarkan buku direktori Ikatan Akuntan Indonesia tahun 2011 yang membedakan Kantor Akuntan Publik Berafiliasi Asing dan Kantor Akuntan Publik Lokal. Untuk variabel Tingkat Profesionalisme yang digunakan ialah variabel yang dikembangkan oleh Snizek (1972) dalam Swailes (2003) yang merupakan pengembangan dari hasil penelitian Hall (1968) yang menilai profesionalisme auditor menjadi lima dimensi atau indikator yaitu dedikasi terhadap profesi, keyakinan terhadap standar profesi, kewajiban sosial, kebutuhan otonomi, dan afiliasi dengan sesama profesi serta komitmen organisasi.

\section{Teknik Analisa Data Uji Reliabilitas dan Validitas Data}

Adapun prosedur yang dilakukan dalam mengukur kualitas data tersebut ialah Uji konsistensi internal (reliabilitas) dan Uji validiatas data. Uji konsistensi internal (reliabilitas) yang ditentukan melalui koefisien Cronbach Alpha. Pengujian ini menentukan konsistensi jawaban responden atas suatu pertanyaan dalam instrumen penelitian. Hair et al. (1996) menyatakan bahwa suatu instrumen yang dikatakan memenuhi syarat reliabel atau dapat dihandalkan apabila koefisien Cronbach Alpha diatas 0,70.

Uji validitas data digunakan untuk mengukur seberapa tinggi tingkat validitas suatu instrumen yaitu dalam hal ini ialah kuesioner. Hair et al. (1998) menyatakan bahwa uji validitas dilakukan dengan menghitung korelasi antara skor masing-masing bagian pertanyaan dalam kuesioner dengan seluruh total skor dari setiap item-item pertanyannya, apabila hasil uji validitas dengan menggunakan software penelitian yaitu SPSS yang biasa digunakan menghasilkan output yang didalamnya termuat bahwa korelasi antar skor dari pertanyaan-pertanyaan terhadap seluruh total skor profesionalisme menunjukkan hasil yang signifikan 0,05 (5\%). Maka berdasarkan hasil tersebut dapat disimpulkan bahwa masing-masing pertanyaan adalah valid.

\section{Uji Hipotesis}

Penelitian ini bertujuan untuk melihat perbedaan tingkat profesionalisme kerja auditor dalam tiga aspek yaitu perbedaan jenis kelamin, perbedaan jabatan, serta perbedaan jenis afiliasi tempat auditor bekerja (KAP afiliasi asing dan KAP lokal). Pengujian ini dilakukan untuk melihat ada atau tidaknya perbedaan tingkat profesionalisme secara fakta dan realita melalui alat uji statistik dari tiap-tiap 
variabel independen. Peneliti menggunakan uji $\mathrm{F}$ (F-test) untuk mencari hasil dari aspek yang diteliti karena dinilai paling sesuai dengan materi yang diujikan. Dalam pengujian ini peneliti menyatakan menerima atau menolak hasil penelitian sebelumnya. Dengan cara membandingkan nilai probabilitasnya dengan tingkat signifikansi yang telah ditentukan ialah sebesar $5 \%$ atau 0,05 .

\section{PEMBAHAHASAN}

Melihat dari hasil uji ketiga hipotesis. Pertama, aspek profesionalisme kerja dan jenis kelamin tidak terdapat perbedaan profesionalisme kerja auditor pria dan auditor wanita. Hal ini sesuai dengan penelitian yang diungkapkan oleh Pillsbury, et al (1989) yang menyatakan bahwa komitmen karir dan profesionalisme tidak terkait dengan gender. Serta Pillsbury et al. (1989) dalam (Ioana, 2007), menunjukan bahwa antara pria dan wanita mempunyai peluang dan tingkat profesionalisme yang sama. Tetapi, berdasarkan hasil uji ini membuktikan bahwa pernyataan dari Lehman (1992) dalam (Reed et al., 1994), tidak dapat diterima. Lehman (1992), menyatakan bahwa wanita sulit menyeimbangkan diri pada tanggung jawab profesionalnya, karakteristik akuntan sebaiknya lebih pada maskulinitas, sehingga dapat ditarik kesimpulan bahwa yang lebih cocok untuk menjadi seorang akuntan ialah laki-laki. Wanita pada zaman sekarang telah memiliki pola pikir yang lebih maju yaitu pertimbangan terhadap keluarga tetap ada, tetapi tidak pula mengurangi tingkat profesionalismenya dalam pekerjaan. Sehingga antara pria dan wanita masing-masing memiliki keunggulan dalam melakukan pekerjaan dalam profesinya. Hal ini juga diungkapkan oleh Mutmainah (2006), yang menyatakan bahwa profesi akuntan juga cocok untuk wanita karena keunggulannya dalam ketelitian, kecermatan, dan tingkat kerajinannya untuk telaten dalam melakukan setiap pekerjaannya. Sehingga ketika pria dan wanita memiliki kesempatan untuk berkarir pada posisi jabatan dan pelatihan yang sama maka akan menunjukkan prioritas etis yang sama. Pernyataan tersebut mengindikasikan hasil bahwa tingkat profesionalisme auditor pria dan auditor wanita tidak berbeda apabila perlakuan dari kantor akuntan publik adil.

Kedua, berdasarkan aspek profesionalisme kerja dan jabatan auditor dalam kantor akuntan publik diketahui bahwa terdapat beda yang signifikan antara auditor dalam setiap jabatannya. Tingkat profesionalisme kerja auditor berubah seiring dengan lamanya bekerja. Penelitian ini mendukung pernyataan dari Lekatompessy (1999), yang menyatakan bahwa terdapat perbedaan sikap profesionalisme pada jabatan auditor di Kantor Akuntan Publik. Hal ini juga sesuai dengan hasil penelitian Walker (1998) dalam (Vinciguerra, 2005), yang menyatakan bahwa semakin tinggi jabatan auditor maka akan semakin rentan untuk dipengaruhi oleh klien. Kemudian, berdasarkan hasil dari penelitian Vinciguerra (2005), ditemukan bahwa penilaian auditor dalam penugasan masih lemah (lower assestment) sehingga etika bisa mempengaruhi hasil audit. Penelitian ini menolak pernyataan dari Jimbalvo, et al (1979), yang hasil penelitiannya menemukan bahwa semakin tinggi jabatan auditor maka semakin tinggi tingkat profesionalismenya. Serta hasil penelitian Goezt, et al., (1991) dalam (Shafer, et al., 2002), meneliti ukuran kantor akuntan publik dan penilaian jabatan terhadap tingkat profesionalisme akuntan. Penelitian tersebut mengindikasikan adanya keyakinan bahwa profesi akan menyediakan layanan pada publik. Pelayanan tersebut berhubungan dengan ukuran kantor akuntan publik dan tingkatan jabatan yang menunjukkan kekuatan yaitu jabatan yang lebih tinggi berkaitan dengan tingkat profesionalisme yang lebih tinggi.

Hal ini terbukti berdasarkan hasil uji LSD Post Hock yang menunjukkan hasil yang signifikan perbedaan profesionalisme kerja antara junior auditor - manager, senior auditor manager, serta manager - partner. Berdasarkan hasil survey dan pengamatan diketahui bahwa pada kantor akuntan publik orientasi dari 
junior auditor dan senior auditor itu lebih pada mengerjakan segala penugasan sesuai dengan standar yang berlaku. Manager lebih pada memberikan kemudahan pada klien dan kompromi terhadap hasil temuan. Partner pada kantor akuntan publik sebagai penanggung jawab dari hasil laporan audit yang dikeluarkan oleh kantor akuntan publik. Perbedaan orientasi inilah yang mengakibatkan perbedaan tingkat profesionalisme kerja para auditor di kantor akuntan publik. Hasil survey tersebut dikuatkan berdasarkan hasil penelitian terdahulu yaitu auditor mengalami perubahan etika seiring dengan lamanya bekerja, akibat dari flexiblitas pekerjaan yang tinggi. Kemudian Cohen dan Single (2001), menyatakan bahwa semakin tinggi tingkat flexibilitas kerja auditor maka akan berpengaruh negatif terhadap etika. Flexibiltas pekerjaan yang tinggi akan menghilangkan rasa perduli kepada sesama auditor. Orientasi auditor tidak lagi untuk kesuksesan seluruh kantor akuntan publik (Goal Conqruance), tetapi lebih memikirkan untuk kesuksesan terhadap pribadinya (untuk peningkatan jabatannya). Berdasarkan temuan ini dapat diindikasikan bahwa semakin tinggi jabatan auditor maka akan semakin tinggi tingkat flexibilitas kerjanya (tingkat pekerjaannya) yang hal tersebut kemungkinan besar mengakibatkan menurunnya tingkat profesionalisme auditor.

Perbedaan profesionalisme dalam tingkat jabatan juga terjadi karena terdapat dilema antara partner maupun manager dengan klien yang memberikan pekerjaan untuk melakukan audit. Hal ini terkait dengan keinginan klien untuk mendapatkan penilaian hasil audit yang baik, sedangkan auditor dituntut untuk profesional dalam mengungkap semua hal dalam proses auditnya. Sehingga, terjadi konflik kepentingan dalam proses tersebut.

Ketiga, kantor akuntan publik dilihat berdasarkan aspek jenis afiliasi yaitu afiliasi asing dan afiliasi lokal diketahui bahwa tidak terdapat perbedaan profesionalisme kerja. Hal ini mengindikasikan bahwa sekarang auditor pada kantor akuntan publik lokal mampu meningkatkan profesionalisme kerjanya. Penelitian ini mendukung Lekatompessy (1999), yang menyatakan bahwa tidak ada perbedaan profesionalisme kerja akuntan dilihat dari besar kecilnya kantor akuntan publik. Sehingga terbukti bahwa kantor akuntan publik lokal telah berbenah untuk dapat bersaing dengan kantor akuntan publik afiliasi asing. Serta kantor akuntan publik afiliasi asing masih ada yang terlibat dalam kasus atau skandal yang mengakibatkan menurunnya tingkat kepercayaan klien. Hal itulah yang memberikan dampak yang positif bagi kantor akuntan publik lokal. Pernyataan tersebut sejalan dengan Harahap (2002), yang menyatakan ukuran kantor akuntan publik tidak dapat menjadi jaminan bahwa semakin besar suatu kantor akuntan publik akan semakin profesional dalam melaksanakan tugasnya.

Tabel 1. Hasil Uji Beda

\begin{tabular}{|c|c|c|c|c|}
\hline Variabel & Gender & Mean & Sig. & Keterangan \\
\hline \multirow{3}{*}{$\begin{array}{l}\text { Tingkat } \\
\text { profesionalisme kerja }\end{array}$} & Pria & 2,961 & \multirow{3}{*}{0,104} & \multirow{3}{*}{$\begin{array}{c}\text { F hitung }<F \text { tabel } \\
\text { Tidak Signifikan }\end{array}$} \\
\hline & Wanita & 2,847 & & \\
\hline & Total & 2,896 & & \\
\hline & Jabatan & Mean & & \\
\hline \multirow{5}{*}{$\begin{array}{c}\text { Tingkat } \\
\text { profesionalisme kerja }\end{array}$} & Junior auditor & 2,898 & \multirow{5}{*}{0,007} & \multirow{5}{*}{$\begin{array}{c}\mathrm{F} \text { hitung }>\mathrm{F} \text { tabe } \\
\text { Signifikan }\end{array}$} \\
\hline & Senior auditor & 3,018 & & \\
\hline & Manager & 2,566 & & \\
\hline & Partner & 2,972 & & \\
\hline & Total & 2,896 & & \\
\hline \multirow{4}{*}{$\begin{array}{l}\text { Tingkat } \\
\text { profesionalisme kerja }\end{array}$} & Tipe KAP & Mean & & \\
\hline & Afiliasi Asing & 2,885 & \multirow{3}{*}{0,728} & \multirow{3}{*}{$\begin{array}{c}\text { F hitung }<F \text { tabel } \\
\text { Tidak Signifikan }\end{array}$} \\
\hline & Lokal & 2,910 & & \\
\hline & Total & 2,896 & & \\
\hline
\end{tabular}




\section{PENUTUP}

\section{Simpulan}

Pertama, berdasarkan aspek jenis kelamin ditemukan bahwa tidak terdapat perbedaan yang signifikan antara auditor pria dan auditor wanita dalam profesional kerjanya. Pekerjaan auditor tidak hanya cocok bagi pria tetapi pekerjaan ini juga dapat dilakukan oleh seorang wanita (Mutmainah, 2006). Mutmainah (2006), memaparkan bahwa profesi akuntan juga cocok untuk wanita karena keunggulannya dalam ketelitian, kecermatan, dan tingkat kerajinannya untuk telaten dalam melakukan setiap pekerjaannya. Auditor pria dan auditor wanita masing-masing memiliki keunggulan dan kelemahan. Oleh karena itu, dapat disimpulkan bahwa bias gender pada zaman sekarang sudah mulai berkurang.

Kedua, berdasarkan aspek jabatan ditemukan kenyataan baru bahwa terdapat perbedaan tingkat profesionalisme kerja auditor dari jabatan junior auditor sampai dengan partner. Perbedaan orientasi dalam pekerjaan mengakibatkan terjadiya perbedaan tersebut serta pengaruh intensitas dan flexibilitas pekerjaan merubah sikap, perilaku, dan etika auditor seiring dengan jabatan yang diembannya (Cohen dan Single, 2001).

Ketiga, auditor yang bekerja pada kantor akuntan publik afiliasi asing dan auditor yang bekerja di kantor akuntan publik lokal tidak terdapat perbedaan tingkat profesionalisme kerja. Temuan ini mendukung hasil dari penelitian Lekatompessy (1999) yang menyatakan bahwa tidak ada perbedaan profesionalisme kerja auditor dilihat dari tipe kantor akuntan publik.

\section{Saran}

Berdasarkan hasil penelitian, ada banyak hal yang masih perlu dilakukan oleh peneliti selanjutnya. Penelitian harus lebih mengungkapkan secara terinci tingkat profesionalisme kerja auditor di Pulau Jawa khususnya dan di Indonesia pada umumnya. Untuk itu perlu ditambahkan lagi variabel-variabel yang dapat menjadi indikator dalam menilai tingkat profesionalisme kerja selain yang telah ada dalam penelitian ini, agar semua faktor tercakup didalamnya. Untuk itu perlu tambahan referensi baik dari jurnal, artikel, serta buku. Perlu persiapan yang matang sebelum menyebarkan kuesioner dengan terlebih dahulu menghubungi kantor akuntan publik. Sehingga, penyebaran kuesioner dapat lebih merata kesemua objek penelitian di semua daerah tujuan penelitian.

Peneliti selanjutnya dapat juga membuat penelitian seperti ini dengan lebih menonjolkan pada seberapa tinggi tingkat profesionalisme kerja auditor di Indonesia. Tingkat profesionalismenya dengan peringkat tinggi, rendah, dan sedang atau dengan penilaian $\mathrm{A}, \mathrm{B}, \mathrm{C}$, dan D. Serta, mencari variabel-variabel yang dapat mempengaruhi peningkatan maupun penurunan tingkat profesionalisme kerja. Penelitian ini sangat menarik dan bagus karena masih jarang dilakukan.

\section{DAFTAR PUSTAKA}

Aranya, and K. Ferris. 1983. "Organizational-professional conflict among U.S. and Israeli professional accountants." Journal of Social Psychology 119: 153-161.

Cohen, Aaron, and Yardena K., 2004, "Professionalism and organizational citizenship behavior: An empirical examination among Israeli."Journal of Managerial Psychology; 2004; 19, 4; Abi/Inform.

Cohen, Jeffrey R. and Single, Louise E, 2001, "An examination of the perceived impact of flexible work arrangements on professional opportunitie." Journal of Business Ethics; Aug 2001; 32, 4.

Fogarty, Timothy J;Singh, Jagdip;Rhoads, Gary K;Moore, and Ronald K., 2000, "Antecedents and consequences of burnout in accounting: Beyond the role stress model." Behavioral Research in Accounting; 2000; 12, Abi/Inform.

Hunton, JE.;Presha E. Neidermeyer, and Benson Weir. 1995. "Hierarchical and Gender Differences in Private Accounting Practice," Accounting Horizons, Vol 10 No. 2 June 1996.

Kalbers and Timothy Fogarty. 1995. "Profesionalismand 
Consequences: A Study of internal Aduitor," Journal of Practice \&Theory, Vol. 14 No. 1.

Kalbers and Timothy Fogarty, 2000, "An empirical evaluation of the interpersonal and organisational correlates of professionalism in internal auditing." accounting and iimt Biiiim-sa Research. Vol. .10. No. 1. pp. 125-I.W. Moo.

Kalbers and Cenker, 2007, "Organizational commitment and auditors in public accounting." Managerial Auditing Journal Vol. 22 No. 4, 2007 pp. 354-375.

Lekatompessy, J.E. 2003. "Hubungan Profesionalisme dengan konsekuensinya: Komitmen Organisasional, Kepuasan Kerja, Prestasi Kerja dan Keinginan Berpindah (Studi Empiris di Lingkungan Akuntan Publik)." Jurnal Bisnis dan Akuntansi, Vol.5, No.1, April.

Lupu, Ioana, 2007, "Women in the French accountancy profession: the test of the labyrinth." GREG - CRC, Conservatoire National des Arts et Métiers (Paris) Académie d'Etudes Economiques Bucarest.

Muthmainah, Siti, 2006, "Studi Tentang Perbedaan Evaluasi Etis, Intensi Etis (Ethical Intention) dan Orientasi Etis Dilihat Dari Gender dan Disiplin Ilmu: Potensi Rekruitmen Staf Profesional Pada Kantor Akuntan Publik." Universitas Diponegoro.

Nur Indriantoro dan Bambang Supomo, 1999, "Metodologi Penelitian Bisnis, untuk Akuntansi dan Manajemen." BPFE Yogyakarta, Edisi pertama.

Pratt, J dan P Beaulieu, 1992. "Organizational Culture in Public Accounting: Size, Technology, Rank and Functional area." Accounting Organization and Society, Vol. 17, No. 7, p. 667-684.

Richard H. Hall, 1968, "Professionalism and Bureaucratization", American Sociological Review.

Sekaran, Uma. 2006. Metodologi Penelitian Untuk Bisnis, Buku 2. Salemba Empat. Jakarta.

Shafer, William E.; Park, L. Jane, and Liao, Woody M., 2002, "Pofessionalism, organizationalprofessional conflict and work outcomes: A study of certified management acoountant." Accounting, Auditing, \& Accountability Journal;2002;15,1; Abi/Inform.

Snizek.. W., 1972, 'Hall's Professionalism Scale: An Empirical Reassessment." American Sociological Review, WoUl. "No.], pp. 109-14.

Sofyan. S. Harahap. 2002. Teori Akuntansi. Edisi Revisi. PT. Raja Grafindo Persada. Jakarta.

Swailes, Stephen, 2003."Professionalism: Evolution and measurement." The Service Industrial Journal Vol. 23 Issue 2, p130-149, 20p, 2 Charts.

Vinciguerra M. Barbara. 2005. "Auditor Independence: An Examination Independence Risk Factors and Mitigating Factors on Auditor Judgment." School of Graduate Professional Studies. Penn State Great Valley. 